\title{
Hierarchical analysis of mtDNA variation and the use of mtDNA for isopod (Crustacea: Peracarida; Isopoda) systematics
}

\author{
R. Wetzer \\ Invertebrate Zoology, Crustacea, Natural History Museum of Los Angeles County, 900 Exposition Blvd., \\ Los Angeles, CA 90007,USA, rwetzer@nhm.org
}

Keywords: 12S rRNA, 16S rRNA, COI, mitochondrìal DNA; isopod, Crustacea, molecular

\begin{abstract}
Carefully collected molecular data and rigorous analyses are revolutionizing today's phylogenetic studies. Although molecular data have been used to estimate various invertebrate phylogenies for more than a decade, this study is the first survey of different regions of mitochondrial DNA in isopod crustaceans assessing sequence divergence and hence the usefulness of these regions to infer phylogeny at different hierarchical levels. I evaluate three loci from the mitochondrial genome (two ribosomal RNAs $(12 \mathrm{~S}, 16 \mathrm{~S})$ and one protein-coding (COI)) for their appropriateness in inferring isopod phylogeny at the suborder level and below. The patterns are similar for all three loci with the most speciose suborders of isopods also having the most divergent mitochondrial nucleotide sequences. Recommendations for designing an order- or suborder-level molecular study in previously unstudied groups of Crustacea would include: (1) collecting a mininum of two-four species or genera thought to be most divergent, (2) sampling across the group of interest as equally as possible in terms of taxonomic representation and the distribution of species, (3) surveying several genes, and (4) carrying out preliminary alignments, checking data for nucleotide bias, transition/ transversion ratios, and saturation levels before committing to a large-scale sequencing effort.
\end{abstract}

\section{Contents}

Introduction

Materials and methods

Sources of specimens and DNA preservation

DNA extraction, primers, $\mathrm{PCR}$ amplification, and sequencing

Sequence alignment strategy

Determining nucleotide composition, sequence divergence, and transition/transversion bias

Results

GenBank submission

Nucleotide composition

Sequence divergence
Transition/transversion bias $\quad 30$

Discussion

Nucleotide composition

Transition/transversion bias

Sequence divergences

Rate variation across lineages

Conclusions

Acknowledgements

References

\section{Introduction}

The crustacean order Isopoda is important and interesting because it has a broad geographic distribution and is morphologically diverse. There are more than 10,000 described marine, freshwater, and terrestrial species, ranging in length from 0.5 $\mathrm{mm}$ to $440 \mathrm{~mm}$. They are common inhabitants of nearly all environments, and most groups are freeliving. Many are scavengers or grazers, although some are temporary or obligatory parasites of fishes and other crustaceans. Many species are shallow water inhabitants, but some taxa are well adapted to life in the deep sea, subterranean groundwater, and thermal springs. Isopods are members of the superorder Peracarida, and a synapomorphy of the superorder is a brooding life style (there are no free-living larvae; development is direct with young emerging with the adult morphology) and thus there is purported poor dispersal ability.

The first isopod was described in 1764 (Asellus -Geoffroy), and the group's systematics and taxonomy has been bantered about ever since. Present workers recognize ten suborders, and over the past twenty years isopods have received considerable 
morphological systematic attention, with ordinal summaries provided by Bowman and Abele 1982, Brusca and Iverson 1985, Schram 1986, Wägele 1989, and Brusca and Wilson 1991. Morphological character-based, cladistic analyses have been carried out for several isopod taxa (e.g., idoteid and arcturid valviferans, Brusca 1984, Poore 1995; corallanid flabelliferans, Delaney 1989; phreatoicids, Wägele 1989; janírid asellotans, Wilson 1994; serolids, Brandt 1988, 1992).

Molecular techniques have invigorated crustacean systematics over the last dozen years with primary contributions stemming from higher-level systematics. A comprehensive list of molecular phylogenetic studies carried out to date for the Crustacea at the species level and higher appears in Table 1. No published studies exist within the Isopoda, although several mitochondrial (mt) DNA studies based on the 16S ribosomal RNA (rRNA) gene are in progress (suborders of Isopoda, Dreyer, Ph.D. díssertation, Ruhr-Universität Bochum; species of Thermosphaeroma, Davis et al., in review; and genera and families of Oniscidea, Michel, Université de Poitiers).

As researchers turn to molecular methods, mtDNA is being used to address both higher-level systematics and population-level questions. However, there are pitfalls when using inappropriate sequence data for phylogenetic inference. Selecting a gene for phylogenetic analysis requires matching the level of sequence variation to the desired taxonomic level of study. Several recent papers have focused on the identification of genes that are useful for phylogenetic analysis at different taxonomic levels (Brower and DeSalle 1994, Friedlander et al. 1994, Graybeal 1994, Simon et al. 1994, Sullivan et al. 1995). Mitochondrial 12S- and 16S rRNA genes and the protein-coding cytochrome oxidase c subunit I (COI) gene have been studied extensively within recently diverged lineages of arthropods $(<5$ million years ago, mya). Sea urchins and butterflies exhibit similar divergence rates for a given gene, with the rate linear with time and $1.8-2.3 \%$ divergence per million years (Bermingham and Lessios 1993, Brower 1994). However, when more ancient lineages (>75 mya) of vertebrates are compared, different mtDNA genes vary considerably with respect to divergence rate, i.e., some genes are more conserved than others (Cummings et al. 1995). Understanding basic parameters such as patterns of nucleotide substitution and rate variation among sites is important for proper application of DNA sequence data to molecular systematic studies (Yang 1994, Yang and Kumar 1996, Blouin et al. 1998, Whitfield and Cameron 1998).

Mitochondrial 12S rRNA, 16S rRNA, and COI genes are attractive to crustacean evolutionary biologists because universal and crustacean-specific primers are readily available for polymerase chain reaction (PCR; Saiki et al. 1988) amplification, and amplified gene fragment sizes are amenable to manual and automated sequencing techniques. Comparative arthropod sequences are known for these genes and extracting sufficient and adequate quality DNA from ethanol-preserved specimens of highly variable preservation are attainable goals for organisms with a considerable range in body size. By describing patterns of sequence divergence within and among populations, species, genera, families, and suborders of isopods, the appropriateness of three mitochondrial genes for evolutionary questions at various taxonomic levels can be determined.

\section{Material and methods}

\section{Sources of specimens and DNA preservation}

The taxa used at each taxonomic (hierarchical) level of comparison are shown in Table 2. The suborder Flabellifera may not be a monophyletic taxon (Kussakin 1979, Bruce 1981, Wägele 1989, Brusca and Wilson 1991), and relationships of the families included within the Flabellifera have also been controversial. In this study flabelliferan families are considered separate taxonomic entities and in figures are referred to by the family name followed by "(Flabellifera)." Most specimens were collected by the author; additional specimens were donated by colleagues (see Acknowledgements). Most specimens were fixed and preserved in $95 \%$ ethanol, and in some instances DNA was extracted from specimens fixed in $70-75 \%$ ethanol. The latter specimens had body sizes $>10 \mathrm{~mm}$. 
Table 1. Molecular phylogenetic studies withìn Crustacea at the species level and higher with studies grouped by taxa. Genes studied include nuclear 18S rRNA, mitochondrial 12S- and $16 \mathrm{~S}$ rRNAs, and protein-coding mitochondrial cytochrome oxidase c subunit I (COI) gene fragments.






\section{DNA extraction, primers, PCR amplification, and sequencing}

Debris and ectoparasites were shaken off specimens by submerging them in deionized water and exposing them to ultrasound waves for 5-10 seconds. Specimens were then rinsed 3-4 times in deionized water. Since isopods vary considerably in body size, two different extraction protocols were used. DNA from specimens less than $3 \mathrm{~mm}$ in length was extracted using a standard phenol-chloroform protocol (Cunningham and Buss 1993). Appendages (antennae, pereopods, or pleopods) were dissected off specimens larger than $5 \mathrm{~mm}$ and tissue similarly extracted. Alternatively, $25 \mathrm{mg}$ of tissue (entire specimen, anterior, or posterior half of specimen) were extracted using the QIAamp Tissue Kit (Qiagen, Inc., Valencia, CA). One to four $\mu \mathrm{l}$ of DNA template were used in 50- $\mu$ PCR reactions.

The COI sequence was amplified using the Folmer et al. (1994) universal primers (LCO1490 and $\mathrm{HCO} 2198$, 442 base pairs, bp), and Palumbi et al. (1991) universal 16Sar and 16Sbr primers were used for the 16S rRNA fragment ( $\sim 378 \mathrm{bp})$. A $~ 275$ bp region of the 12S rRNA gene was amplified using peracarid specific primers (12SCRF: 5'-GAG AGT GAC GGG CGA TAT GT-3'; 12SCRR: 5'-AAA CCA GGA TTA GAT ACC CTA TTA T-3').

For the PCR reaction, Perkin Elmer (Foster City, CA) or Promega (Madison, WI) 10X buffer and the manufacturer's respective Taq DNA polymerase (2.5 units) were used with an initial denaturation period of 3 minutes at $95^{\circ} \mathrm{C}$, followed by 35 cycles at $94^{\circ} \mathrm{C}$ for 15 seconds and extension for 1.5 minutes at $72^{\circ} \mathrm{C}$. Annealing temperatures ranged from $48^{\circ} \mathrm{C}$ (COI) to $52^{\circ} \mathrm{C}$ (12S rRNA and $16 \mathrm{~S}$ rRNA) for 1 minute. PCR amplification product (3-6 $\mu \mathrm{l}$ ) was electrophoresed through an ethidium bromidestained $1-2 \%$ agarose gel, and the product was checked for proper size. Remaining PCR product was purified with polyethylene glycol (PEG) or with Sephadex G-50 (Sigma Chemical, Inc.) and Centrisep columns (Princeton, Separations, Adelphia, NJ), or if necessary, gel purified using the Qiagen Gel Purification Kit. DNA was then cycle sequenced with ABI (Applied Biosystems Inc., Foster City, CA) Big Dye terminators, and both strands were sequenced on an ABI 377 automated sequencer. Nucleotide sequences were edited using the Sequencher software package (ver. 3.1, GeneCodes Corp., Ann Arbor, MI), and sequences were searched for similarity to other arthropods using BLAST (Basic Local Alignment Search Tool, URL: http://www.ncbi.nlm.nih.gov/BLAST/index. $\mathrm{html})$. Additionally, the accuracy of COI sequences was verified by translating nucleotides to amino acids with MacClade 3.06 (Maddison and Maddison 1996), and all sequences were verified for proper reading frame.

\section{Sequence alignment strategy}

Thirty-three COI sequences were aligned by hand since there were no insertions or deletions of nucleotides or amino acids. One data set was prepared for amino acid and a second data set for nucleotide analyses. The multiple-sequence-alignment program CLUSTAL W 1.74 (Gibson et al. 1996) was set to default settings (slow/accurate gap open penalty = 15.00 , gap extension penalty $=6.66, k$-tuple size $=2$, transitions not weighted) and used to align 49 and $1816 \mathrm{~S}$ rRNA and 12S rRNA sequences, respectively.

\section{Determining nucleotide composition, sequence divergence, and transition/transversion bias}

The essential component of genomic structure are the two linear polynucleotide chains composed of two purines (adenine [A] and guanine [G]) that hydrogen-bond to two pyrimidines (thymine [T] and cytosine [C], respectively). Nucleotide frequency can result in taxon- and gene-specific patterns of nucleotide composition. The phylogenetic analysis program PAUP* version 4.062 (Swofford 1999) was used to determine nucleotide composition.

A method of summarizing the relationship between two sequences is by their fraction (or percentage) of similarity or dissimilarity. In its simplest form, the similarity is equal to the number of aligned sequence positions containing identical residues (bases or amino acids) divided by the number of 


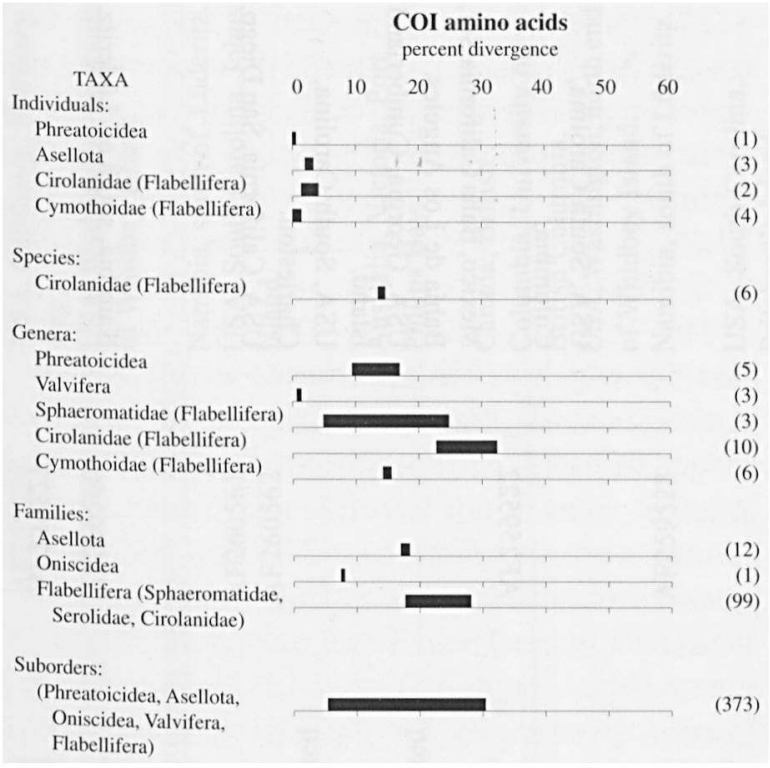

Fig. I. Percent divergence ("uncorrected p") for cytochrome oxidase c subunit I (147 amino acids, 33 taxa) plotted against taxonomic level. Minimum and maximum divergence measure expressed as range (bar). Number of pairwise comparisons indicated in parentheses on right.

sequence positions being compared. Dissimilarity is merely the proportion (p) of nucleotide sites (n) at which the two sequences being compared are different $\left(n_{d}\right), p=n_{d} / n$. For example, if two taxa are represented by 20 aligned nucleotides and they differ at 5 sites, the "uncorrected p" value is 0.25 . These two sequences can also be said to have $75 \%$ similarity.

Percent-sequence divergence ("uncorrected p") values obtained using PAUP* are summarized in Figs. 1-4 for COI amino acids, COI nucleotides, $16 \mathrm{~S}$ rRNA, and 12S rRNA within individuals, species, genera, families, and suborders. Sequence comparisons were made at the lowest taxonomic level possible. For example, for COI amino acids (Fig. 1), the two sphaeromatids Sphaeramene and Sphaeroma were compared at the genus level. Since only one species in each genus was sequenced, this was the only comparison possible at this hierarchial level. Plots in all instances represent sequences of individuals from a single specimen lot, i.e., a single population, except Caecidotea (Asellota) which comes from two populations a few kilometers apart. All other collection localities ranged in area from 0.5 to $3 \mathrm{~m}^{2}$. In the case of the fish ectoparasite
Lironeca vulgaris (Cymothoidae), the data are from two ovigerous females from which two individual young (mancas) were removed and for this analysis treated as "individuals."

Transition/transversion (ti/tv) tables were generated from the same data sets as above with PAUP* and plotted with a program written by N. D. Pentcheff (unpublished) (Fig. 5). The number of transitions versus the number of transversions in all pairwise comparisons of COI, $16 \mathrm{~S}$ rRNA, and $12 \mathrm{~S}$ rRNA sequences are corrected for sequence length variation by dividing the $\mathrm{t} i / \mathrm{tv}$ ratio by the number of nucleotides in each sequence.

\section{GenBank submission}

GenBank accession numbers for sequences listed in Table 2 are as follows: COI sequences AF255775AF255791, AF260834-AF260846, 16S rRNA sequences AF259531-AF259547, AF260847AF260870, and 12S rRNA sequences AF259521AF259530, AF260558-AF260562, AF260564.

\section{Results}

\section{Nucleotide composition}

Nucleotide composition of COI, 16S rRNA, and $12 \mathrm{~S}$ rRNA sequences are provided in Table 3 . COI nucleotide composition is reported for all three codon positions: first and second positions only, and third positions alone. The $G$ statistic for the log-likelihood ratio goodness-of-fit test was used to determine whether nucleotide composition was equal within a given gene. A nucleotide bias ( $\mathrm{p}<$ 0.001 ) was found for all genes. For COI (all positions) there is roughly a $7 \% \mathrm{~A}+\mathrm{T}$ bias. The $\mathrm{A}+\mathrm{T}$ bias nearly disappears when third positions are removed, yet Ts are favored over As. COI third positions alone are ca. $68 \% \mathrm{~A}+\mathrm{T}$. Both ribosomal RNA genes have nearly equal $\mathrm{A}+\mathrm{T}$ composition (ca. $58 \%$ and $62 \% \mathrm{~A}+\mathrm{T}$ for $16 \mathrm{~S}-$ and $12 \mathrm{~S}$ rRNA, respectively). 


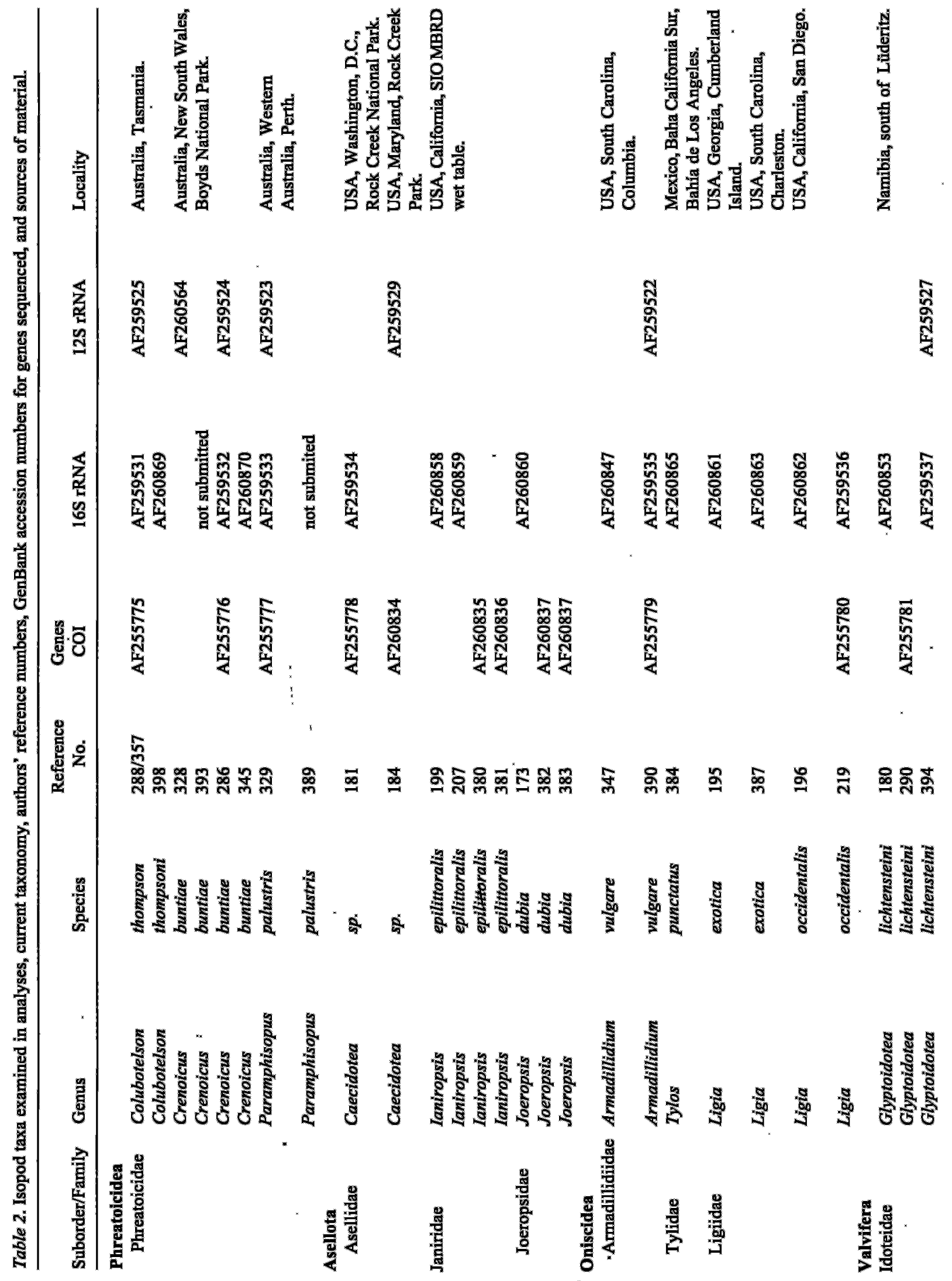




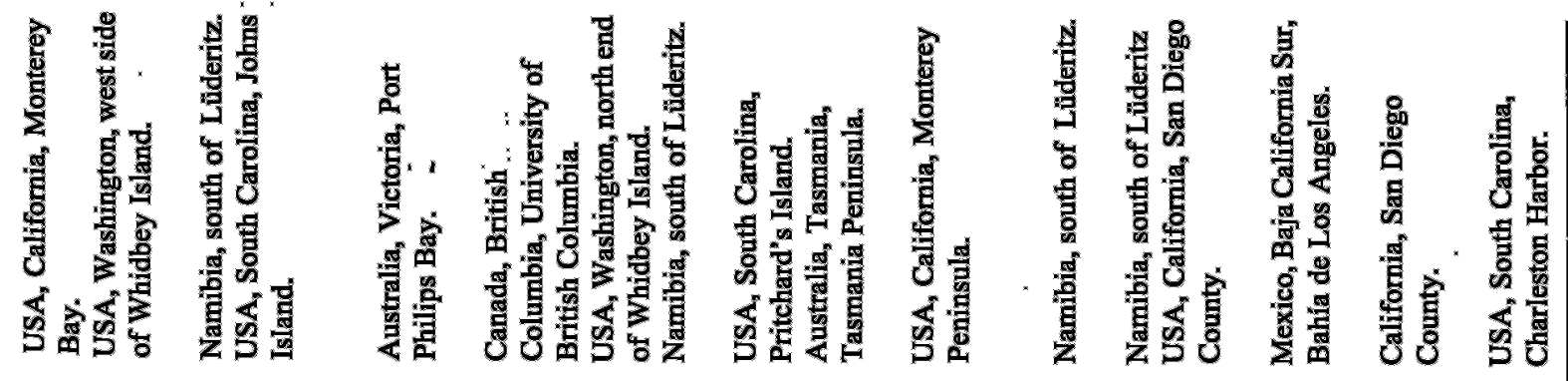

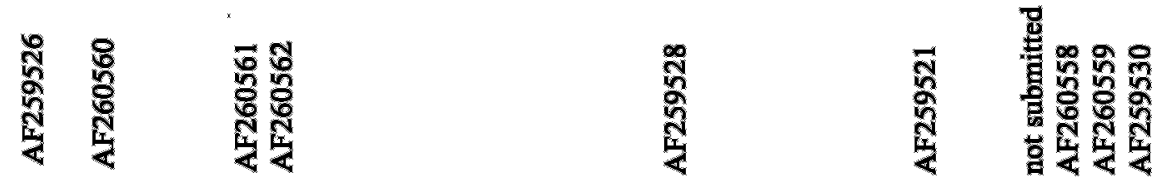

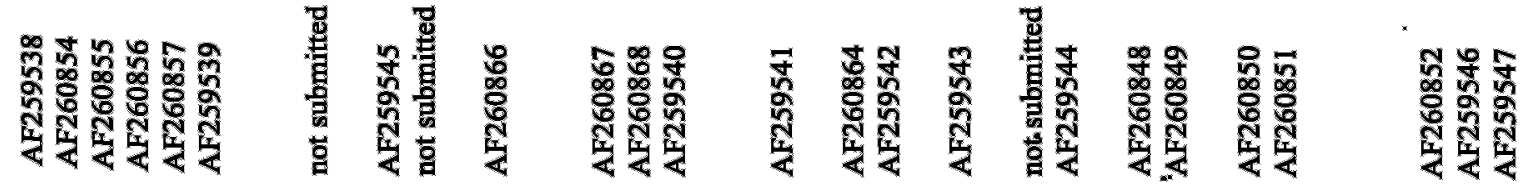

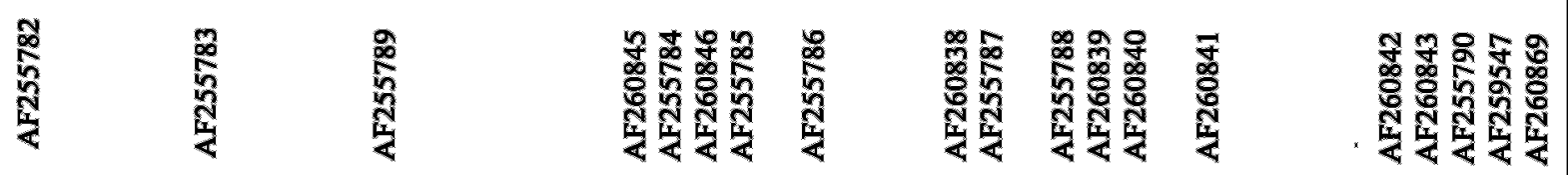

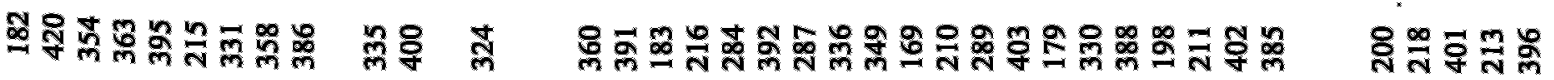

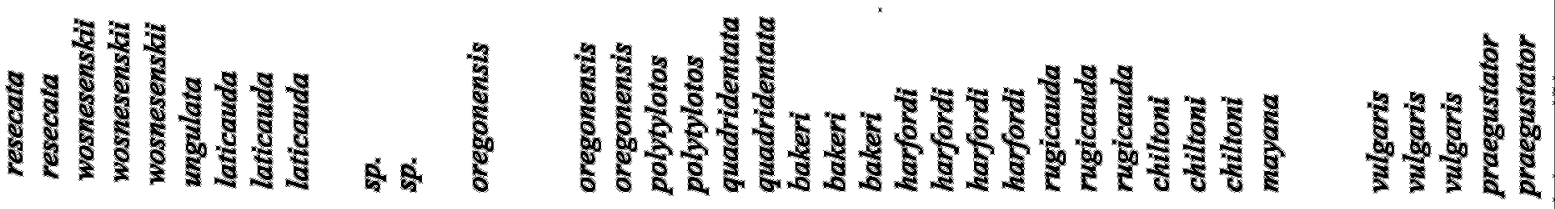

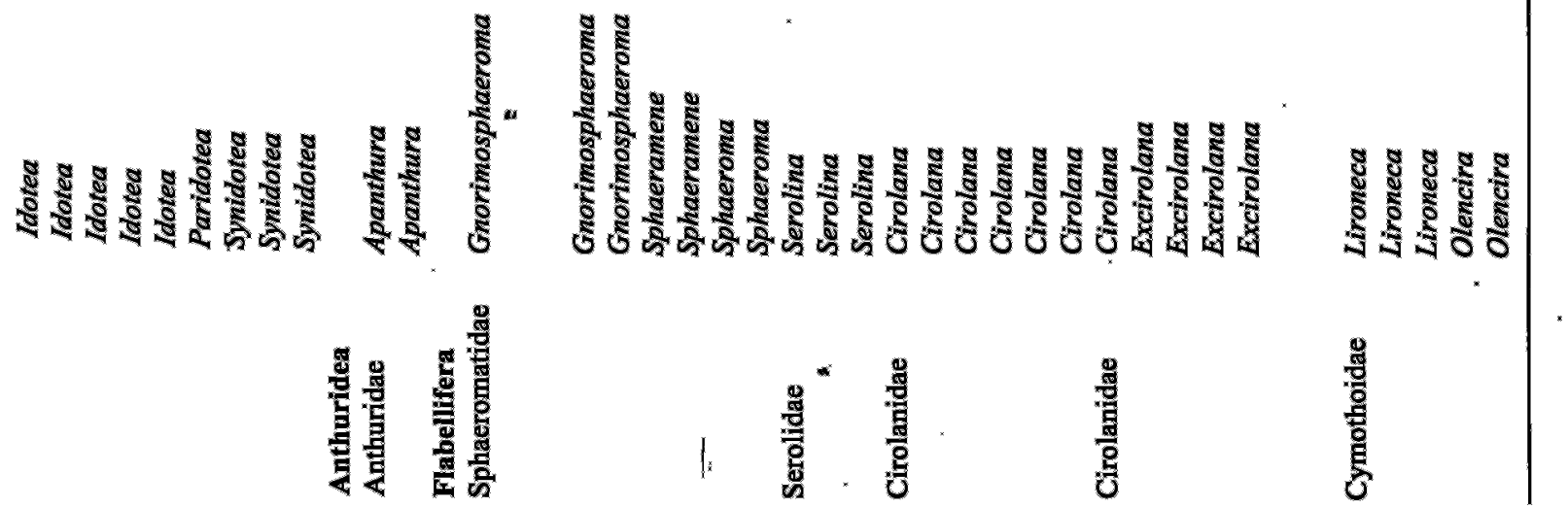


Table 3. Nucleotide composition and sequence length (total number of nucleotides) for all isopods surveyed. $A=$ adenine, $\mathbf{T}=$ thymine, $\mathbf{C}=$ cytosine, $\mathbf{G}=$ guanine. Numeric values in parentheses following COI represent codon positions included in calculations. Values for nucleotides expressed as percent of total. The log-likelihood ratio goodness-of-fit test (G stat) was significant for all gene sequences $(\mathrm{p}<0.001)$, $\mathrm{df}=\mathbf{3}$.

\begin{tabular}{llllllr}
\hline $\begin{array}{l}\text { Gene } \\
\text { sequence }\end{array}$ & A & T & C & G & $\begin{array}{l}\text { Total No. } \\
\text { Nucleo- } \\
\text { tides }\end{array}$ & G stat \\
\hline COI $(1,2,3)$ & 23.6 & 37.3 & 19.5 & 19.6 & 442 & 1141 \\
COI (1, 2) & 19.6 & 35.1 & 22.4 & 22.9 & 295 & 521 \\
COI (3) & 31.6 & 41.5 & 13.7 & 13.2 & 147 & 1142 \\
16S rRNA & 35.8 & 29.9 & 16.3 & 18.0 & 378 & 1997 \\
12S rRNA & 32.8 & 32.7 & 14.8 & 19.7 & 275 & 521 \\
\hline
\end{tabular}

\section{Sequence divergence}

Figures 1-4 summarize the pairwise sequence divergence for COI amino acids and nucleotides, and 16S- and 12S rRNA sequences. These data are arranged in taxonomic (hierarchical) fashion with minimum and maximum sequence divergences observed for each taxonomic ranking.

The COI comparisons for $\mathbf{3 3}$ taxa are shown in Figs. 1 and 2. This data set is based on 442 bases, i.e., 147 amino acids. Note all sequences were truncated to the length of the shortest sequence to eliminate spurious values due to unequal sequence length. Figure 1 summarizes the amino acid comparisons. For individuals from the same population pairwise sequence divergence ranged from $0-4.1 \%$. Phreatoicid sequences were identical, and comparisons of Asellota ranged from $0.7-2.0 \%$. Comparisons among individuals from populations of Flabellifera are reported separately (see Methods, for discussion of taxonomic treatment of Flabellifera taxa) for the members of the family Cirolanidae (1.4-4.1\%) and Cymothoidae (0-1.4\%). Comparisons of species of the flabelliferan family Cirolanidae were observed to have 13.6-14.7\% sequence divergences. At the genus level, five hierarchical comparisons could be made with values ranging between 9.5$32 \%$ for all comparisons. At the family level, three hierarchical comparisons could be made with the flabelliferan families exhibiting the largest range, $17.7-33.6 \%$. The largest range was clearly exhibited by the flabelliferan family Sphaeromatidae.
The same 33 taxa were used in the nucleotide comparisons (Fig. 2). Overall, these comparisons were comparable to amino acid divergence patterns. Here values for comparisons of individuals ranged from $0-3.2 \%$, species $32.9-34.9 \%$, genera 15.8 $37.6 \%$, families $22.9-34.5 \%$, and across suborders 20.7-35.5\%.

The 16S rRNA data set (Fig. 3) contained 49 taxa for which 429 aligned bases were compared. Among individuals, pairwise sequence divergences ranged from 0-2.7\%. Specimens of Oniscidea (Ligia exotica) from South Carolina and Georgia populations were separated by $\sim 240 \mathrm{~km}$, and the sequences obtained are identical. Sequence divergences for oniscid, valviferan, and cirolanid species comparisons ranged from $14.5-21.3 \%$. Acrossgenera divergences for phreatoicids, asellotans, valviferans, sphaeromatids, cirolanids, and cymothoids ranged from $8.9-49.1 \%$. Of these comparisons, the Cirolanidae exhibit the greatest divergences (38.9-49.1\%). Familial comparisons ranged from $34.4-49.1 \%$. The subordinal comparisons were 28.2-49.1\%.

The 12S rRNA data set (Fig. 4) contained 18 taxa for which 312 aligned bases were used in comparisons. Three comparisons of individuals from single populations were possible. The two phreatoicid sequences were identical, the two valviferan sequences were $4.3 \%$ dissimilar, and the six cirolanid sequence comparisons were $47-52 \%$ dissimilar. The trend toward increasing sequence divergences is maintained for taxonomic levels from species to genera to families to suborder, with the greatest value reaching $50.2 \%$.

\section{Transition/transversion bias}

A frequently used measure of substitutions is the calculation of transitions (ti) and transversions (tv). Transitions are substitutions between $\mathbf{A}$ and $\mathbf{G}$ (purines) or between $\mathrm{C}$ and $\mathrm{T}$ (pyrimidines). Transversions are substitutions between a purine and a pyrimidine. Generally, transitions occur more frequently than transversions, even though for any given nucleotide position twice as many possible transversions may occur as transitions. Figure 5 illustrates the transition/transversion (ti/tv) values 


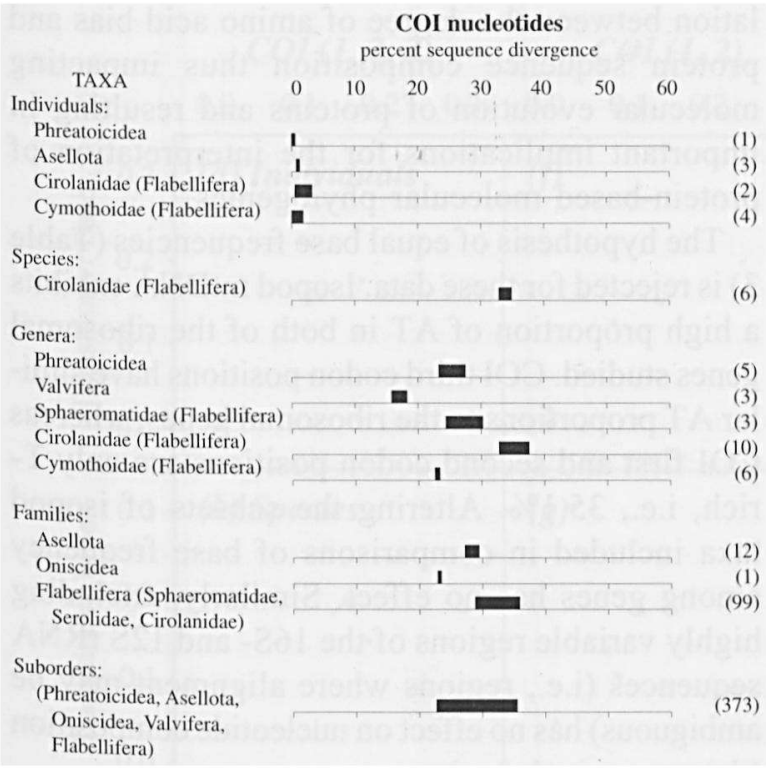

Fig. 2. Percent sequence divergence ("uncorrected p") for cytochrome oxidase c subunit I (442 bases, 33 taxa) plotted against taxonomic level. Minimum and maximum divergence measure expressed as range (bar). Number of pairwise comparisons indicated in parentheses on right.

corrected for sequence length for each hierarchical comparison (individual, species, genus, family, and suborder) as discussed previously. During the preparation of Fig. 5, the importance of correcting ti/tv ratios for sequence length became obvious when comparing multiple genes, and although some studies have depicted $\mathrm{ti} / \mathrm{tv}$ plots with regression lines, the non-independence of transitions and transversions make such depictions inappropriate (Purvis and Bromham 1997).

Excluding third codon positions (Fig. $5 \mathrm{f}-\mathrm{j})^{1}$ reduces ti/tv ratios (compare Fig. $5 \mathrm{a}-\mathrm{e}$ to $5 \mathrm{f}-\mathrm{j}$ ). These results suggest that for suborder-, family-, and possibly genus-level comparisons, the third positions are saturated. In the $\mathrm{ti} / \mathrm{tv}$ ratio comparisons for individuals, species, and genera (Fig. $5 \mathrm{a}, \mathrm{f}, \mathrm{k}, \mathrm{l}$, $\mathrm{m}, \mathrm{p}, \mathrm{q}$, and $\mathrm{r}$ ), the data points fall into roughly two clusters. This is in part the result of the number and kinds of taxonomic comparisons possible with this data set and reflects the larger divergences observed for the flabelliferan families Cirolanidae and Sphaeromatidae relative to all other isopods.

\footnotetext{
'note sequence comparisons are identical in Figure $5 \mathrm{a}-\mathrm{e}$ and
$5 \mathrm{f}-\mathrm{j}$
}

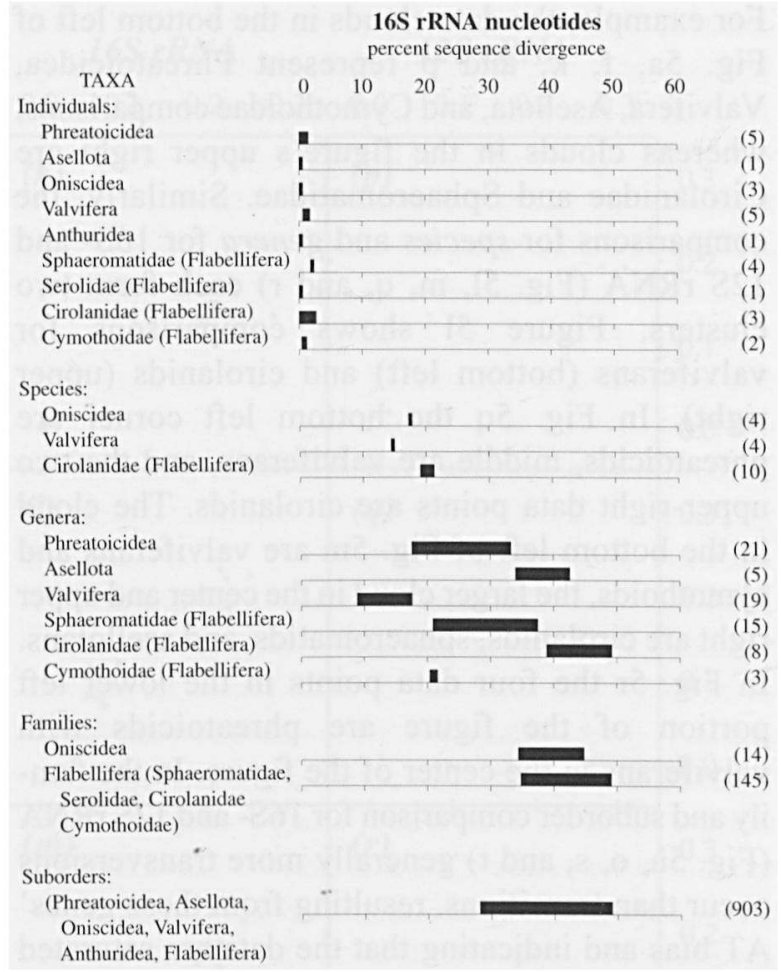

Fig. 3. Percent sequence divergence ("uncorrected p") for $16 \mathrm{~S}$ rRNA (429 aligned bases, 49 taxa) plotted against taxonomic level. Minimum and maximum divergence measure expressed as range (bar). Number of pairwise comparisons indicated in parentheses on right.

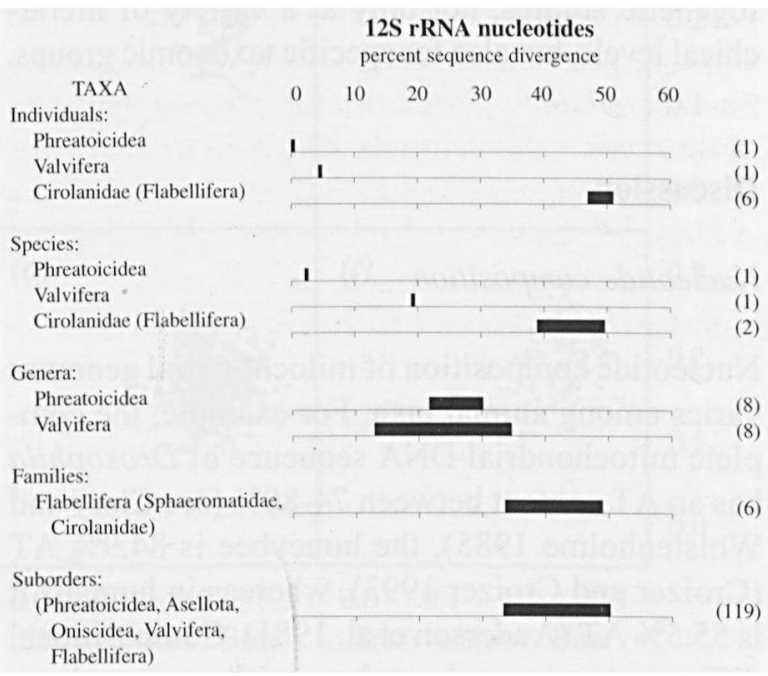

Fig. 4. Percent sequence divergence ("uncorrected p") for $12 \mathrm{~S}$ rRNA (312 aligned bases, 18 taxa) plotted against taxonomic - level. Minimum and maximum divergence measure expressed as range (bar). Number of pairwise comparisons indicated in parentheses on right. 
For example, the data clouds in the bottom left of Fig. 5a, $f, k$, and $p$ represent Phreatoicidea, Valvifera, Asellota, and Cymothoidae comparisons, whereas clouds in the figure's upper right are Cirolanidae and Sphaeromatidae. Similarly, the comparisons for species and genera for 16S- and 12S rRNA (Fig. 51, m, q, and r) each form two clusters. Figure 51 shows comparisons for valviferans (bottom left) and cirolanids (upper right). In Fig. 5q the bottom left corner are phreatoicids, middle are valviferans, and the two upper-right data points are cirolanids. The cloud in the bottom left of Fig. $5 \mathrm{~m}$ are valviferans and cymothoids, the larger cloud in the center and upper right are cirolanids, sphaeromatids, and asellotans. In Fig. $5 r$ the four data points in the lower left portion of the figure are phreatoicids with valviferans in the center of the figure. In the family and suborder comparison for 16S- and 12S rRNA (Fig. 5n, o, s, and t) generally more transversions occur than transitions, resulting from these genes" AT bias and indicating that the data are saturated (i.e., increasing homoplasy masks phylogenetic signal) at these hierarchical levels. In Fig. 5t, the lone data point at the bottom left is a comparison of a cirolanid to an oniscid, clearly two distant taxa whose low ti/tv value reflects saturation. These findings have broad implications for isopod phylogenetíc studies, not only at a variety of hierarchical levels, but also for specific taxonomic groups.

\section{Discussion}

\section{Nucleotide composition}

Nucleotide composition of mitochondrial genomes varies among animal taxa. For example, the complete mitochondrial DNA sequence of Drosophila has an AT content between 74-80\% (see Clary and Wolstenholme 1985), the honeybee is $84.9 \%$ AT (Croizer and Croizer 1993), whereas in humans it is 55.5\% AT (Anderson et al. 1981). Compositional differences among homologous sequences have been attributed to both variation in selective constraints and changes in mutation patterns during evolutionary divergence (Perna and Kocher 1995). Singer and Hickey (2000) found a postitive corre- lation between the degree of amino acid bias and protein sequence composition thus impacting molecular evolution of proteins and resulting in important implications for the interpretation of protein-based molecular phylogenies.

The hypothesis of equal base frequencies (Table 3 ) is rejected for these data. Isopod mtDNA exhibits a high proportion of $\mathrm{AT}$ in both of the ribosomal genes studied. COI third codon positions have similar AT proportions to the ribosomal genes, whereas COI first and second codon positions are only $\mathrm{T}$ rich, i.e., 35.1\%. Altering the subsets of isopod taxa included in comparisons of base frequency among genes has no effect. Similarly, excluding highly variable regions of the $16 \mathrm{~S}-$ and $12 \mathrm{~S}$ rRNA sequences (i.e., regions where alignment may be ambiguous) has no effect on nucleotide composition (data are not shown).

Overall these data suggest that isopod crustaceans examined here have a smaller AT bias compared to insects. Still, isopod AT bias is more similar to insects and other molting organisms (Ecdysozoa) (e.g., nematodes, Blouin et al. 1998) than to humans. An artifact of AT-rich mtDNA is that taxa have a tendency to group in phylogenetic analyses based more on shared nucleotide composition than on shared history (Hasegawa et al. 1993, Steel et al. 1993), underscoring the importance of appropriate substitution models when estimating phylogenetic relationships. The findings herein are congruent with the 16S rRNA data for Australian freshwater crayfish genera (Lawler and Crandall 1998), which also found an $A T$ bias: $A=32.2 \%, T=35.3 \%$, $\mathrm{C}=10.8 \%$, and $\mathrm{G}=21.7 \%$. Similarly, Hanner and Fugate's (1997) study found the 12S rRNA gene of branchiopod crustacean orders to have an average AT bias of $\mathrm{A}=34.3 \%$ and $\mathrm{T}=31.9 \%$. The findings of Funk et al. (1995) for phytophagus beetles revealed not only a stronger AT bias compared to what has been found in crustaceans, but the AT bias was greater for the 16S rRNA gene than for the COI gene (AT bias for 16S rRNA: $A=37.3 \%$, $\mathrm{T}=41.2 \%$; $\mathrm{COI}: \mathrm{A}=28.9 \%, \mathrm{~T}=37.1 \%$ ). Whitfield and Cameron's (1998) study of hymenopteran taxa exhibited the greatest proportions of AT nucleotides of any organism yet measured. For the 16S rRNA gene, these workers found the mean percent $A+T$ to be $82.2 \%$ with the AT content highest in groups 


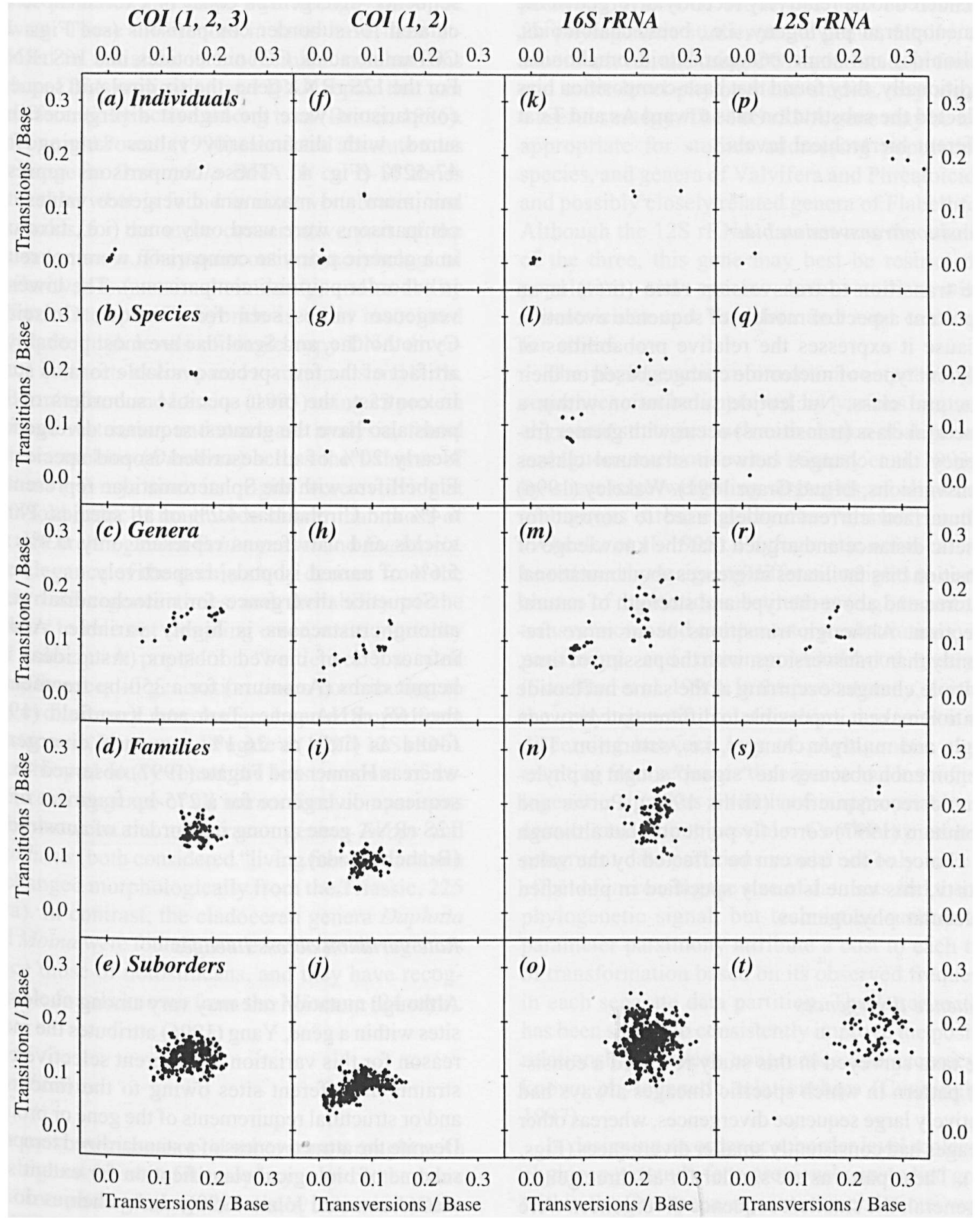

Fig. 5. Number of transitions versus number of transversions in all pairwise comparisons of COI, 16S rRNA, and 12S rRNA sequences corrected for sequence-length variation (Pentcheff, unpublished). COI first, second, and third codon positions (COI 1,2,3) are summarized in the first column (a-e). COI first and second codon positions (COI 1,2) are represented in the second column (f-j). 16S rRNA and $12 \mathrm{~S}$ rRNA are summarized in the third and fourth columns, k-o and $\ddot{p}-t$, respectively. This figure gives an indication of the extent of transition/transversion bias and the extent of saturation in substitutions among different hierarchical levels. Some points overlap one
another. 
considered to be relatively recently diverged in the hymenopteran phylogeny, i.e., bees, chalcidoids, scelionids, and some endoparasitoid brachonids. Additionally, they found that base-composition bias reflected the substitution bias toward As and Ts at different hierarchical levels.

\section{Transition/transversion bias}

The transition-to-transversion ratio (ti/tv) is an important aspect of models of sequence evolution because it expresses the relative probabilities of different types of nucleotide changes based on their structural class. Nucleotide substitution within a structural class (transitions) occur with greater frequency than changes between structural classes (transversions; Li and Graur 1991). Wakeley (1996) summarized current models used to correct for genetic distance and argued that the knowledge of transition bias facilitates inferences about mutational patterns and about the type and strength of natural selection. Although transitions occur more frequently than transversions, with the passing of time, multiple changes occurring at the same nucleotide position make it impossible to differentiate between single and multiple changes, i.e., saturation. This phenomenon obscures the "signal" sought in phylogenetic reconstruction (Hillis 1991). Purvis and Bromham (1997) correctly point out that although the choice of the tree can be affected by the value of $t i / t v$, this value is rarely specified in published molecular phylogenies.

\section{Sequence divergences}

The taxa surveyed in this study revealed a consistent pattern in which specific lineages always had relatively large sequence divergences, whereas other lineages had consistently smaller divergences (Figs. 1-4). These patterns are similar for all three genes. In general, the smallest sequence divergences were observed for members of the suborders Phreatoicidea and Valvifera, and the largest divergences observed among members of the flabelliferan families Sphaeromatidae and Cirolanidae. For example, in some generic comparisons of Cirolanidae the sequence divergences equal or exceed those calculated for suborder comparisons (see Figs. 1-3; COI amino acids, COI nucleotides, and 16S rRNA). For the 12S rRNA gene, the six cirolanid sequence comparisons were the highest divergences measured, with dissimilarity values ranging from $47-52 \%$ (Fig. 4). These comparisons represent minimum and maximum divergence values, and comparisons were used only once (i.e., taxa used in a generic pairwise comparison were not reused in suborder pairwise comparisons). The lower divergence values seen for Asellota, Oniscidea, Cymothoidae, and Serolidae are most probably an artifact of the few species available for this study. In contrast, the most speciose suborders of isopods also have the greatest sequence divergences. Nearly $20 \%$ of all described isopod species are Flabellifera with the Sphaeromatidae representing $6.4 \%$ and Cirolanidae $4.2 \%$ of all species. Phreatoicids and valviferans represent only $0.9 \%$ and $5.6 \%$ of named isopods, respectively.

Sequence divergence for mitochondrial genes among crustaceans is highly variable. Among infraorders of clawed lobsters (Astacidea) and hermit crabs (Anomura) for a 350-bp fragment of the 16S rRNA gene, Tam and Kornfield (1998) found as little as $26.1 \%$ sequence divergence, whereas Hanner and Fugate (1997) observed $46.8 \%$ sequence divergence for a 275-bp fragment of the 12S rRNA gene among infraorders of anostracans (Branchiopoda).

\section{Rate variation across lineages}

Although mutation rate may vary among nucleotide sites within a gene, Yang (1996) attributes the major reason for this variation to different selective constraints at different sites owing to the functional and/or structural requirements of the gene or protein. Despite the attractiveness of a standardized temporal scheme of biological classification for extant species (Avise and Johns 1999), such schemes do not account for highly unequal evolutionary rates among lineages. For example, Britten (1986) measured a 5-fold rate change between different vertebrate and invertebrate groups. Rodents, sea urchins, and Drosophila have the fastest evolving DNA, whereas 
higher primates and some bird lineages have the slowest. These differences in rates have been attributed to variation in biochemical mechanisms such as DNA replication and DNA repair that can be differentially active among taxa (Britten 1986). Caccone and Powell (1990) calculated absolute rates of change in Drosophila DNA as ca. 5-10 times faster than what is found in most vertebrates, and this holds for the more conservative part of the nuclear genome. They point out that morphological similarity, chromosomal similarity, and/or ability to form interspecific hybrids is often associated with quite high levels of single-copy DNA divergence in insects as compared to mammals and birds.

Bermingham and Lessios (1993) using 23 protein loci and restriction endonuclease analysis, found that sea urchins (Diadema) across the Isthmus of Panama ( $\sim 3$ mya since its origin) were evolving at a 10-fold order of magnitude slower than those of the two urchin genera Echinometra and Eucidaris. The elegance of the urchin study derives from the known divergence times and the ability of the authors to rule out sampling error, mass mortality and subsequent population "bottleneck", as well as differences in generation times contributing to this evolutionary rate change. In an example from crustaceans, Hanner and Fugate's (1997) 12S rRNA branchiopod study found the least amount of sequence divergence of all intraordinal comparisons to be between the notostracan genera Triops and Lepidurus (both considered "living fossils" and both unchanged morphologically from the Triassic, 225 mya). In contrast, the cladoceran genera Daphnia and Moina were found to have sequence divergences twice those of notostracans, and they have recognizable fossils known from the Miocene (24 mya).

\section{Conclusions}

The most speciose isopod subordèrs, wrought with the highest levels of homoplasy, can be the bane of a morphological systematist's existence. On a molecular level, these same groups may also have the most divergent mitochondrial nucleotide sequences. For all three genes, members of the suborder Flabellifera have the most divergent DNA. Based on the ti/tv ratios (Fig. 5), eliminating third positions from COI sequences may be desirable for phylogenetic studies at the genus, family, and suborder level, and using COI amino acids in familyand order-level phylogenetic studies may also be a useful strategy. The 16S rRNA gene may be most appropriate for studies addressing populations, species, and genera of Valvifera and Phreatoicidea, and possibly closely related genera of Flabellifera. Although the 12S rRNA data set was the smallest of the three, this gene may best be restricted to population and species level studies within Phreatoicidea and Valvifera and used cautiously for others.

The phylogenetic information content of gene sequences can be improved by various sequence alignment strategies such as exclusion of alignmentambiguous nucleotide sites (Gatesy et al. 1993) or by successive weighting strategies of alignmentambiguous sites, e.g., by the "elision" method (Wheeler et al. 1995). Phylogenetic noise can also be reduced by assigning different weights to certain classes of nucleotide substitutions (e.g., transitions, transversions, and compensatory substitutions) into parsimony and maximum-likelihood analyses (Swofford et al. 1996). In the present study, in which the phylogenetic relationships are unknown, discerning between loss of phylogenetic signal resulting from sequence divergence and loss of phylogenetic signal as a result of inappropriate taxonomic rank is not possible. Combining multiple congruent data partitions would not only have the effect of increasing the size of data sets and thereby phylogenetic signal, but techniques such as sixparameter parsimony attribute a cost to each type of transformation based on its observed frequency in each separate data partition. The latter method has been shown to consistently improve the positive relationship between congruence and accuracy of known phylogenetic relationships (Cunningham 1997).

In designing an order or suborder level molecular phylogenetic study for a previously unstudied group within the Crustacea, my recommendations would include: (1) collection of a minimum two to four species or genera thought to be most divergent, i.e., most distantly related (this may include taxa which are the most speciose, have unusual lifestyles, morphology, and/or have had a tumultuous taxo- 
nomic history); (2) obtain as equal a representation of taxa across the group as possible; (3) survey two to three genes, if possible, (alignment problems are greatly reduced by using protein-coding genes; single copy nuclear genes); (4) carry out preliminary alignments, check data for nucleotide bias, ti/tv ratios, and saturation levels before committing to a large-scale sequencing effort.

\section{Acknowledgements}

I thank members of my dissertation committee Bruce Coull, Joe Quattro, Sally Woodin, and Jon Ahlquist for their helpful suggestions and careful reviews of the manuscript. I am especially grateful to Travis Glenn, Trisha Spears, Scott France, and Bob vanSyoc for their extremely helpful technical advice, both at the bench and with the analyses, as well as their invaluable discussions on molecular techniques and phylogenetics. I thank Dean Pentcheff for writing computer programs which immensely aided in data presentation, and for his thoughtful and clear-minded suggestions from whỉch thís work has benefited. This research was supported by the National Science Foundation, Dissertation Improvement Grant DEB-9701524; University South of Carolina, American Museum of Natural History, Theodore Roosevelt Memorial Fund; Abele/Spears Laboratory, Florida State University, Tallahassee; Slocum-Lunz Foundation; Sigma Xi, Grants-in-Aid of Research; and by grants from the Environmental Protection Agency and Department of Energy to Bruce Coull, I thank Todd Haney and two anonymous reviewers for their invaluable comments on the manuscript.

Colleagues who contributed specimens are gratefully acknowledged: A. Richardson, University of Tasmania, Hobart, Australia; G. Wilson, Australian Museum, Sydney, Australia; T. Spears and S. Boyce, Florida State University, Tallahassee, Florida; D. Sanger, Marine Resources, Charleston, South Carolina; T. J: Hilbish, University of South Carolina, Columbia, South Carolina; G. C. B. Poore, Museum of Victoria, Melbourne, Australia; T. Stebbins, City of San Diego, San Diego, California; R. Wiseman and C. Biernbaum, College of Charleston, Charleston, South Carolina.

\section{References}

Abele LG. 1991. Comparison of morphological and molecular phylogeny of the Decapoda. Mem. Queensland Mus. 31: 101-108.

Abele LG, Kim W, Felgenhauer BE. 1989. Molecular evidence for inclusion of the phylum Pentastomida in the Crustacea. Mol. Biol. Evol. 6: 685-691.

Abele LG, Spears T, Kim W, Applegate M. 1992. Phylogeny of selected maxillopodan and other crustacean taxa based on $18 S$ ribosomal nucleotide sequences: a preliminary analysis. Acta Zool. (Stockholm) 73: 373-382,
Anderson S, Bankier AT, Barrell BG et al. (14 coauthors). 1981. Sequence and organization of the human mitochondrial genome. Nature 290: 457-465.

Avise JC, Johns GC. 1999. Proposal for a standardized temporal scheme of biological classification for extant species. Proc. Nat. Acad. Sci. 96: 7358-7363.

Bermingham E, Lessios HA. 1993. Rate variation of protein and mtDNA evolution as revealed by sea urchins separated by the Isthmus of Panama. Proc. Nat. Acad. Sci. 90: 27342738.

Blouin MS, Yowell CA, Courtney CH, Dame JB. 1998. Substitution bias, rapid saturation, and the use of mtDNA for nematode systematics. Mol. Biol. Evol. 15: 1719-1727.

Bowman TE, Abele LG. 1982. The classification of Crustacea, In: Abele LG, ed. The Biology of Crustacea, Vol. 1 . Systematics, the Fossil Record, and Biogeography. New York, Academic Press.

Brandt A. 1988. Morphology and ultrastructure of the sensory spine, a presumed mechanoreceptor of the isopod Sphaeroma hookeri (Crustacea, Isopoda) and remarks on similar spines in other peracarids. J. Morph. 198: 219-229.

Brandt A. 1992. Origin of antarctic Isopoda (Crustacea, Malacostraca). Mar. Biol. 113: 415-423.

Britten RJ. 1986. Rates of DNA sequence evolution differ between taxonomic groups. Science 231: 1393-1398.

Brower AVZ. 1994. Rapid morphological radiation and convergence among races of the butterfly Heliconius erato inferred from patterns of mitochondrial DNA evolution. Proc. Nat. Acad. Sci. 91: 6401-6495.

Brower AVZ, DeSalle R. 1994. Practical and theoretical considerations for choice of a DNA sequence region in insect molecular systematics, with a short review of published studies using nuclear gene regions. Ann. Ent. Soc. Am. 87: 702-716.

Bruce NL. 1981. The Cirolanidae (Crustacea: Isopoda) of Australia: new species and a new genus from southeastern Australia. Rec. Aus. Mus. 33: 644-672.

Brusca RC. 1984. Phylogeny, evolution and biogeography of the marine isopod subfamily Idoteinae (Crustacea: Isopoda: Idoteidae). Trans. San Diego Soc. Nat. Hist. 20: 99-134.

Brusca RC, Iverson EW. 1985. A guide to the marine isopod Crustacea of Pacific Costa Rica. Rev. Biol. Trop. 33 (Supplement): 1-77.

Brusca RC, Wilson GDF. 1991. A phylogenetic analysis of the Isopoda with some classificatory recommendations. Mem. Queensland Mus. 31: 143-204.

Bucklin A, Frost BW, Kocher TD. 1992. DNA sequence variation of the mitochondrial 16S rRNA in Calanus (Copepoda; Calanoida): intraspecific and interspecific patterns. Mol. Mar. Biol. Biotech. 1: 397-407.

Bucklin A, Frost BW, Kocher TD. 1995. Molecular systematics of six Calanus and three Metridia species (Calanoida: Copepoda), Mar. Biol. 121: 655-664.

Caccone A, Powell JR. 1990. Extreme rates and heterogeneity in insect DNA evolution. J. Mol. Evol. 30: 273-280.

Casanova J-P, De Jong L, Faure E. 1998. Interrelationships of the two families constituting the Lophogastrida 
(Crustacea: Mysídacea) inferred from morphological and molecular data. Mar. Biol. 132: 59-65.

Clary DO, Wolstenhome DR. 1985. The mitochondrial DNA molecule of Drosophila yakuba: mucleotide sequence, gene organization and genetic codé. 'J. Mol. Evol. 22: 252-271.

Colbourne JK, Hebert PDN. 1996. The systematics of north American Daphnia (Crustacea: Anomopoda); a molecular phylogenetic approach. Phil. Trans. Roy. Soc., London B 351: 349-360.

Crandall KA. 1998. Conservation phylogenetics of Ozark crayfishes: assigning priorities for aquatic habitat protection. Biol. Conserv. 84: 107-117.

Crandall KA, Fitzpatrick JF Jr. 1996. Crayfish molecular systematics: using a combination of procedures to estimate phylogeny. Syst. Biol. 45: 1-26.

Crandall KA, Lawler SH, Austin CM. 1995. A preliminary examination of the molecular phylogenetic relationships of some crayfish genera from Australia (Decapoda: Parasticidae), Fresh. Crayfish 10: 18-30.

Croizer RH, Croizer YC. 1993. The mitochondrial genome of the honeybee Apis mellifera: complete sequence and genome organization. Genetics 133: 97-117.

Cummings MO, Otto SP, Wakeley J. 1995. Sampling properties of DNA sequence data in phylogenetic analysis. Mol. Biol. Evol. 12: 814-822.

Cunningham CW. 1997. Is congruence between data partitions a reliable predictor of phylogenetic accuracy? Empirically testing an iterative procedure for choosing among phylogenetic methods. Syst. Biol. 46: 464-478.

Cunningham CW, Buss LW. 1993. Molecular evidence for multiple episodes of paedomorphosis in the family Hydractinildae. Biochem. Syst. Ecol. 21: 57-69.

Cunningham CW, Blackstone NW, Buss LW. 1992. Evolution of king crabs from hermit crab ancestors. Nature 355: 539-542.

Delaney PM. 1989. Phylogeny and biogeography of the marine isopod family Corallanidae (Crustacea, Isopoda, Flabellifera). Contr. Sci., Los Angeles Co. Nat. Mus, 409: 1-75.

Folmer OM, Black M, Hoeh R, Lutz $R$, Vrijenhoek $\mathbf{R}$. 1994. DNA primers for amplification of mitochondrial cytochrome c oxidase subunit $\mathbf{I}$. from diverse metazoan invertebrates. Mol. Mar. Biol. Biotech. 3: 294-299.

France SC, Kocher TD. 1996. DNA sequencing of formalinfixed crustaceans from archival research collections. $\mathrm{Mol}$. Mar. Biol. Biotech. 5: 304-313.

Friedlander TP, Regier JC, Mitter C. 1994. Phylogenetic information content of five nuclear gene sequences in animals: initial assessment of characte: sets from concordance and divergence studies. Syst. Biol. 43; 511-525.

Funk DJ, Futuyma DJ, Ortí G, Meyer A. 1995. Mitochondrial DNA sequences and multiple data sets: a phylogenetic study of phytophagus beetles (Chysomelidae: Ophraella). Mol. Biol. Evol. 12: 627-640.

Gatesy $J$, DeSalle R, Wheeler W. 1993. Alignment ambiguous nucleotide sites and the exclusion of systematic data. Mol. Phyl. Evol. 2: 152-157.

veller JB, Walton ED, Grosholz ED, Ruiz GM. 1997. Cryptic invasions of the crab Carcinus detected by mole- cular phylogeography. Mol. Ecol. 6: 901-906.

Gibson T, Higgins D, Thompson J. 1996. CLUSTAL W 1.74. http://www-igbme.u-strasbg.fr/BioInfo/ClustalW/.

Graybeal A. 1994. Evaluating the phylogenetic utility of genes: a search for genes informative about deep divergences among vertebrates. Syst. Biol. 43: 174-193.

Hanner R, Fugate M. 1997. Branchiopod phylogenetic reconstruction from 12S rDNA sequence data. $J$. Crust. Biol. 17: 174-183.

Harris DJ, Maxson LS, Braithwiate LF, Crandall KA. 2000. Phylogeny of the thoracican barnacles based on 18S rDNA sequences, J. Crust. Biol. 20: 393-398.

Hasegawa M, Hashìmoto T, Adachi J, Iwabe N, Miyata T. 1993. Early branchings in the evolution of eukaryotes: ancient divergence of entamoeba that lacks mitochondria revealed by protein sequence data. $J . M o l$. Evol. 36: 270281 .

Held C. 2000. Phylogeny and biogeography of serolĩd isopods (Crustacea, Isopoda, Serolidae) and the use of ribosomal expansion segments in molecular systematics. $\mathrm{Mol}$. Phyl. Evol. 15: 165-178.

Hillis DM. 1991. Discriminating between phylogenetic signal and random noise in DNA sequences. In: Miyamoto, MM and J. Cracraft, eds. Phylogenetic Analysis of DNA Sequences. New York: Öxford University Press.

Kim W, Abele LG. 1990. Molecular phylogeny of selected decapod crustaceans based on 18S rRNA nucleotide sequences. J. Crust. Biol. 10: 1-13.

Kitaura J, Wada K, Nishida M. 1998. Molecular phylogeny and evolution of unique mud-using territorial behavior in ocypodid crabs (Crustacea: Brachyura: Ocypodidae). $M o l$. Biol. Evol. 15: 626-637.

Kussakin OG. 1979. Marine and brackish-water Isopoda of cold and temperate (boreal) waters of the Northern Hemisphere. Part 1. Flabellifera, Valvifera, and Tyloidea). [in Russian] Nat. Acad. Sci., U.S.S.R., Zoology 122; 1-470.

Lawler SH, Crandall KA. 1998. The relationship of the Australian freshwater crayfish genera Euastacus and Astacopsis. Proc. Linn. Soc. N. S. W. 119: 1-8.

Lehman N, Pfrender ME, Morin PA, Crease TJ, Lynch M. 1995. A hierarchical molecular phylogeny within the genus Daphnia. Mol. Phyl. Evol. 4: 395-407.

Li W-H, D. Graur D. 1991. Fundamentals of Molecular Evolution. Massachusetts: Sinauer Associates, ${ }^{\times}$Inc.

Maddison WP, Maddison DR. 1996. MacClade. Analysis of Phylogeny and Character Evolution, ver. 3.06. Massachusetts: Sinauer Associates, Inc.

Michel-Salzat A, Bouchon D. 2000. Phylogenetic analysis of mitochondrial LSU rRNA in oniscids. Comp. rend. Acad. Sci. 323: 827-837.

Mizrahi L, Achituv Y, Katcoff DJ, Perl-Treves R. 1998. Phylogenetic position of Ibla (Cirripedia: Thoracica) based on $18 \mathrm{~S}$ rDNA sequence analysis. J. Crust. Biol. 18: 363368.

Palumbí SR, Martin A, Romano S, McMillan WO, Stice L, Grabowski G. 1991. The Simple Fool's Guide to PCR, version 2. Hawaii: University of Hawaii, Honolulu, Department of Zoology and Kewalo Marine Laboratory, 43. 
Patarnello T, Bargelloni L, Varotto V, Battaglia B. 1996. Krill evolution and the Antarctic ocean currents: evidence of vicariant speciation as inferred by molecular data. Mar. Biol. 126: 603-608.

Perl-Treves R, Mizarahi R, Katcoff DJ, Achituv Y. 2000. Elucidation of the phylogenetic relationship of three thecostracans, Verruca, Paralepas, and Dendrogaster based on 18S rDNA sequences. J. Crust. Biol. 20: 385-392.

Perna NT, Kocher TD. 1995. Patterns of nucleotide composition at four-fold degenerate sites of animal mitochondrial genomes. J. Mol. Evol. 41: 353-358.

Ponniah M, Hughes JM. 1998. Evolution of Queensland spiny mountain crayfish of the genus Euastacus Clark (Decapoda: Parastacídae): preliminary 16S mtDNA phylogeny. Proc. Linn. Soc. NSW. 119; 9-19.

Poore GCB. 1995. Australian chaetiliids (Isopodax Valvifera): a new genus, new species and remarks on the family. Mem. Mus. Victoria 46: 153-172.

Purvis A, Bromham L. 1997. Estimating the transition/transversion ratio from independent pairwise comparisons with an assumed phylogeny. J. Mol. Evol. 44: 112-119.

Saíki RK, Gelfand DH, Stoffel S, Scharf SJ, Higuchí $\mathbf{k}$, Horn GT, Mullis KB, Erlich HA. 1988. Primer-directed enzymatic amplification of DNA with a thermostable DNA polymerase. Science 239: 487-491.

Sarver SK, Silberman JD, Walsh PJ. 1998. Mitochondrial DNA sequence evidence supporting the recognition of two subspecies or species of the Florida spiny lobster Panulirus argus. J. Crust. Blol. 18: 177-186.

Schneider-Broussard R, Felder DL, Chlan CA, Neigel JE. 1998. Tests of phylogeographic models with nuclear and mitochondrial DNA sequence variation in the stone crabs, Menippe adina and M. mercenaria. Evol. 52: 16711678.

Schram FR. 1986. Crustacea. New York: Oxford University Press.

Schubart CD, Diesel R, Hedges SB. 1998. Rapid evolution to terrestrial life in Jamaican crabs. Nature 393: 363-365.

Sehubart CD, Neigel JE, Felder DL. 2000a. Use of the mitochondrial 16S rRNA gene for phylogenetic and population studies of Crustacea. In: von Vaupel Klein JC, Schram FR, eds. Crustaceans and the Biodiversity Crisis. Proceedings of the Fourth International Crustacean Congress, Amsterdam, The Netherlands, July 20-24, 1998, vol. 2. Rotterdam, Balkema Press, Crustacean Issues 12: 817-830.

Schubart, CD, Cuesta JA, Diesel R, Felder DL. 2000b. Molecular phylogeny, taxonomy, and evolution of nonmarine lineages within the American grapsoid crabs (Crustacea: Brachyura). Mol. Phyl. Evol. 15: 179-190.

Schubart CD, Reimer J, Diesel R. 1998. Morphological and molecular evidence for new endemic freshwater crab, Sesarma ayatum sp. n., (Grapsịdae, Sesarminae) from eastern Jamaica. Zool. Scripta 27: 373-380.

Simon C, Frati F, Beckenbach A, Crespi B, Liu H, Flook P. 1994. Evolution, weighting, and phylogenetic utility of mitochondrial gene sequences and a compilation of conserved polymerase chain reaction primers. Ann. Ent. Soc. Amer. 87: 671-701.
Singer GAC, Híckey DA. 2000. Nucleotide bias causes a genomewide bias in the amino acid composition of proteins. Mol. Biol. Evol. 17: 1581-1588.

Spears T, Abele LG. 1997. Crustacean phylogeny inferred from $18 \mathrm{~S}$ rDNA. In: Fortey RA, Thomas RH, eds. Systematics Association Special Volume Series 55. London: Chapman and Hall, 169-187.

Spears T, Abele LG. 1999. Phylogenetic relationships of crustaceans with foliaceous limbs: an I8S rDNA study of Branchiopoda, Cephalocarida, and Phyllocarida. J. Crust. Biol. 19: 825-843.

Spears T, Abele LG. 2000. Branchiopod monophyly and interordinal phylogeny inferred from $18 \mathrm{~S}$ ribosomal DNA. J. Crust. Biol. 20: 1-24.

Spears T, Abele LG, Applegate MA. 1994. Phylogenetic study of cirripedes and selected relatives (Thecostraca) based on $18 \mathrm{~S}$ rDNA sequence analysis. $J$. Crust. Biol. 14: 641-656.

Spears T, Abele LG, Kim W. 1992. The monophyly of brachyuran crabs: a phylogenetic study based on 18S rRNA. Syst. Biol. 41: 446-461.

Steele MA, Hendy MD, Penny D. 1993. Parsimony can be consistent! Syst. Biol. 42: 581-587.

Sturmbauer C, Levinton JS, Christy J. 1996. Molecular phylogeny analysis of fiddler crabs: test of the hypothesis of increasing behavioral complexity in evolution. Proc. Nat. Acad. Sci. 93: 10855-10857.

Sullivan J, Holsinger KE, Simon C. 1995. Among-site variation and phylogenetic analysis of $12 \mathrm{~S}$ rRNA in signomonodotin rodents. Mol. Biol. Evol. 11: 261-277.

Swofford DL. 1999. PAUP*, Phylogenetic analysis using parsimony (*and other methods), version 4.062. Massachusetts, Sinauer Associates, Inc.

Swofford DL, Olsen GJ, Waddell PJ, Hillis DM. 1996. Phylogenetic inference. In: Hillis, DM, Moritz, C Mable BK, eds. Molecular Systematics, 2nd edition. Massachusetts, Sinnauer Associates, Inc., 426-446.

Tam YK, Kornfield I. 1998. Phylogenetic relationships of clawed lobster genera (Decapoda: Nephropidae) based on mitochondrial 16S rRNA gene sequences. J. Crust. Biol. 18: $138-146$.

Tam YK, Kornfield I, Ojeda FP. 1996. Divergence and zoogeography of mole crabs, Emerita spp. (Decapoda: Hippidae), in the Americas. Mar. Biol. 125: 489-497.

Taylor DJ, Finston TL, Hebert PDN. 1998. Bíogeography of a widespread freshwater crustacean: pseudocongruence and cryptic endemism in the North American Daphnia laevis complex, Evol. 52: 1648-1670.

vanSyoc RJ. 1995. Barnacle mitochondrial DNA: determining genetic relationships among species of Pollicipes. In: Schram FR, Høeg JT, eds. Crustacean Issues, No. New Frontiers in Barnacle Evolution. Rotterdam, Balkema Press, 269-296.

Wägele J-W. 1989. Evolution und phylogenetisches System der Isopoda. Stand der Forschung und neue Erkenntnisse. Zoologíca 47: 1-262.

Wakeley J. 1996. The excess of transitions among nucleotide substitutions: new methods of estimating transition 
bias underscore its sígnificance. Trends Ecol. Evol. 11: 158-163.

Wheeler W, Gatesy J, DeSalle R. 1995. Elision: a method for accommodating multiple molecular sequence alignments with alignment-ambiguous sitte's. Mol. Phyl. Evol. 4: 1-9.

Whitfield JB, Cameron SA. 1998. Hierarchical analysis of variation in the mitochondrial 16S rRNA gene among Hymenoptera. Mol. Biol. Evol. 15: 1728-1743.

Wilson G. 1994. A phylogenetic analysis of the isopod family Janiridae (Asellota). Invert. Tax. 8: 749-766.
Yang Z. 1994. Estìmating the pattern of nucleotide substitution. J. Mol. Evol. 39: 105-111.

Yang Z. 1996. Among-site rate variation and its impact on phylogenetic analyses. Trends Ecol. Evol. 11: 367-372.

Yang Z, Kumar S. 1996. Approximate methods for estimating the pattern of nucleotide substitution and the variation of substitution rates among sites. Mol. Biol. Evol. 13: 650659.

Received: 20 April 2000 